\title{
Scale structures in discourse: Discourse-pragmatic properties of Japanese comparative expressions
}

\author{
Osamu Sawada*
}

\begin{abstract}
The Japanese sore-yori 'lit. than it' and nani-yori 'lit. than what' have a pragmatic use (in addition to semantic use), and their pragmatic functions are highly discourse-sensitive. In terms of scalarity, the pragmatic sore-yori is non-endpointoriented in that it conventionally implicates that $U$ in sore-yori( $U)$ is preferable to the previous utterance. In contrast, the pragmatic nani-yori is endpoint-oriented in that it conventionally implicates that $U$ in nani-yori $(U)$ is preferable to any alternative utterance. In this paper I argue (i) that these two types of scalar meanings at the level of conventional implicaure (CI) are derived compositionally by the single yori 'than', and (ii) that various kinds of discourse-pragmatic functions of sore-yori and naniyori-such as "topic shifting" in sore-yori, and "priority listing" and "additive reinforcing” in nani-yori-automatically arise from the interaction between the expression's scale structures (endpoint vs. non-endpoint scales) and Grice's conversational maxims (relevance, manner). This paper shows that scale structures play a crucial role in managing the direction of discourse and that there is a rich interaction between CIs and general conversational maxims in pragmatic comparative expressions.
\end{abstract}

Keywords. scale structures; endpoint vs. non-end point scales; discourse; pragmatic comparative expressions; conventional implicatures; Gricean maxims

1. Introduction. In this paper, I will investigate the discourse-dependent pragmatic properties of the Japanese comparative expressions sore-yori 'lit. than it' and nani-yori 'lit. than what' and consider how scalarity and comparison are utilized in discourse structure.

The Japanese comparative expressions sore-yori and nani-yori can be used at the level of semantics, as shown in the following:

Hanako-no keeki-wa sore-yori-(mo) ookii.
Hanako-GEN cake-TOP it-than-MO big
'Hanako's cake is bigger than it/that.'
Kenkoo-ga nani-yori-mo taisetsu-da.
Health-NOM what-than-MO important-PRED
'Health is more important than anything.'

In (1), the sentence with sore-yori compares Hanako's cake with a contextually determined thing (possibly another cake) and denotes that the former is larger than the latter at the level of semantics. In (2), the sentence with nani-yori compares health with contextually related

\footnotetext{
* I would like to thank Tom Grano, Koji Kawahara, Chris Kennedy, Hideki Kishimoto, Kiyomi Kusumoto, Yusuke Kubota, Susumu Kubo, Yo Matsumoto, Sadayuki Okada, Satoshi Oku, Harumi Sawada, Jun Sawada, Eri Tanaka, Daniel Vanderveken, and the audience at LSA 2018 for their valuable comments and suggestions. Parts of this paper were presented at Osaka, Kansai Gaidai, Kobe, and the Actes de discours et conversations workshop in Montreal (2017), and I thank all the audience for their helpful comments and discussions. This paper is based on work supported by JSPS KAKENHI Grant Number 26770140. Author: Osamu Sawada, Mie University (sawadao@human.mie-u.ac.jp).
} 
alternatives (e.g., money, time, position) and semantically denotes that the former is more important than any alternative. ${ }^{1}$

However, sore-yori- $(\mathrm{mo})$ and nani-yori- $(\mathrm{mo})$ can also be used as an utterance modifier at the pragmatic level, as well:

(3) Sore-yori-(mo) syukudai owa-tta?

It-than-MO homework finish-PAST

'Sore yori-mo, did you finish your homework?'

(4) Nani-yori-(mo) Shizuoka-wa ondan-da.

What-than-MO Shizuoka-wa warm-PRED

'More than anything, Shizuoka is warm.'

In (3), sore-yori-mo compares a previous utterance (which is referred to by sore) and the at-issue utterance and denotes that the latter is more important. In (4), nani-yori-mo signals that the atissue is the most important among possible alternatives concerning Shizuoka. ${ }^{2}$

The interesting aspect about the pragmatic use of sore-yori and nani-yori is that their pragmatic functions are highly discourse-dependent. For example, in (5B), sore-yori seems to shift the topic of the conversation (Kawabata 2002) or the discourse goal: ${ }^{3}$

(5) (Example of the pragmatic sore-yori (topic shifting))

A: Sensei osoi-ne?

Teacher late-confirm.Q

'The teacher is late, isn't she?'

B: Sore-yori(-mo) kinoo-no tesuto saiaku-da-tta.

It-than-MO yesterday-GEN test terrible-PRED-PAST

'Sore-yori-mo, yesterday's exam was terrible.'

However, in (6B), sore-yori is not used for shifting the goal or topic of the conversation, but rather it is used for comparing the previous utterance with the given utterance under the same goal (a question under discussion (QUD)(Roberts 1996)):

(6) (Context of denial in goal-internal comparison)

Question: What kind of person is Taro?

A: Taro-wa atama-ga ii-desu.

Taro-TOP head-NOM good-PRED.HON

'Taro is smart.'

B: Iya, sore-yori-(mo) mazu Taro-wa yasashii hito-desu.

No that-than-MO first Taro-TOP kind person-PRED.HON

'No, sore-yori-mo, first, Taro is a kind person.'

The discourse-pragmatic function of the pragmatic nani-yori is also discourse-dependent;

\footnotetext{
${ }^{1}$ Note that $m o$ in (1) is completely optional; however, for many native speakers, mo is necessary in (2). As we will discuss later, mo in a pure comparative sentence (without a wh-phrase) does not have a concrete meaning, whereas mo in a comparison with the indeterminate pronoun nani 'what' has a universal meaning.

${ }^{2}$ Note that unlike the semantic nani-yori, mo in the pragmatic nani-yori is optional. I will explain the difference between the semantic nani-yori-mo and the pragmatic nani-yori-mo in terms of compositionality.

3 In this paper, I use the term "goal” in the sense of Roberts' (1996) notion of "discourse goal," which is the aim to address particular questions in the conversation (i.e., the question under discussion (QUD)). Roberts' notion of discourse goals is different from Vanderveken's (2013) notion of linguistic goals. Vanderveken (2013) proposed the notion of "linguistic goal" based on the idea of speech act or direction of fit.
} 
however, its discourse dependency is quite different from that of the pragmatic sore-yori-mo. As the following examples show, nani-yori can be placed at either the beginning or end of a sequence of utterances, and each use has a different pragmatic effect:

(7) (Example of the pragmatic nani-yori (priority listing))

A: What are the good points of Shizuoka?

B: Nani-yori-(mo) Shizuoka-wa ondan-desu.

What-than-MO Shizuoka-TOP warm-PRED.HON

Soreni tabemono-mo oishii-desu. Kootuu-no ben-mo

And food-also good-PRED.HON. Transportation-GEN convenience-also ii-desu.

good-PRED.HON

'More than anything, Shizuoka is warm. Furthermore, food is good. Also, it is easy to access.'

(8) (Example of the pragmatic nani-yori (additive reinforcing))

A: What are the good points of Shizuoka?

B: Soodesune. Shizuoka-wa koutuu-no ben-ga ii-desu.

Let's see Shizuoka-TOP transportation-GEN convenience-NOM good-PRED.HON

Tabemono-mo oishii-desu. Soshite nani-yori-mo Shizuoka-wa

Food-also good-PRED.HON And what-than Shizuoka-TOP

ondan-desu.

warm-PRED.HON

'Let's see. Shizuoka is easy to access. The food is also good. And more than anything, Shizuoka is warm.'

In (7), nani-yori has the function of priority listing: it behaves like "first of all." On the other hand, nani-yori in (8) is additive reinforcing, as it conveys the most important information at the end of the discourse sequence. In terms of the directionality of the flow of information, nani-yori in (7) uses a top-down strategy, whereas nani-yori in (8) uses a bottom-up strategy.

However, the following questions require further clarification: Why do sore-yori- $(\mathrm{mo})$ and nani-yori- $(\mathrm{mo})$ have these pragmatic functions? Where do the discourse-pragmatic functions of sore-yori-( $\mathrm{mo})$ (goal-shifting/non-goal shifting) and the discourse-pragmatic function of naniyori-( $\mathrm{mo})$ (i.e., priority listing and additive reinforcing) come from? Can we analyze the meaning of sore-yori and nani-yori in a systematic fashion?

In this paper, I will argue that the scale structural properties of the pragmatic sore-yori-mo and nani-yori-mo play an important role in explaining their distinctive pragmatic functions. The pragmatic sore-yori is non-endpoint-oriented, as in (9a), in that it conventionally implicates that $U$ in sore-yori $(U)$ is preferable to the previous utterance. In contrast, the pragmatic nani-yori is endpoint-oriented, as in (9b), in that it conventionally implicates that $U$ in nani-yori( $U)$ is preferable to any alternative utterance (“|” stands for a standard of comparison):

(9) a. Non-maximum endpoint scale

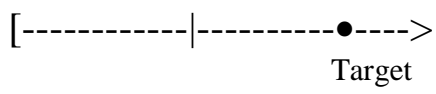

b. Maximum endpoint scale

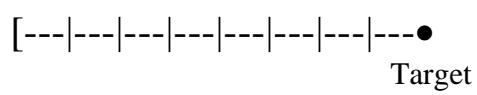


In this paper I will argue (i) that two types of CI scalar meanings are derived compositionally by a single yori 'than' and the elements yori attaches to; and (ii) that various kinds of discoursepragmatic functions of sore-yori and nani-yori-such as "topic shifting" in sore-yori, and "priority listing" and "additive reinforcing" in nani-yori-automatically arise from the interaction between the expression’s scale-structures (i.e., (9a) and (9b)) and Grice’s (1975) conversational maxims (relevance, manner). This paper shows that there are systematic scale structures in the pragmatic dimension and that they are utilized for various pragmatic strategies in a flexible way by interacting with general pragmatic principles.

2. The Japanese sore-yori-(mo) 'than it.' Let us first investigate the meaning and use of soreyori- $(\mathrm{mo})$. We will first look at the interpretation of the semantic sore-yori- $(\mathrm{mo})$ and then consider the meaning and function of the pragmatic sore-yori-(mo).

2.1. THE MEANING OF THE SEMANTIC SORE-YORI-(MO). Let us consider the meaning of semantic sore-yori-(mo) based on (10):

(10) Hanako-no keeki-wa sore-yori-(mo) ookii. Hanako-GEN cake-TOP that-than-MO big

'Hanako's cake is bigger than that.'

Sore-yori-(mo) in (10) is semantic in that its meaning is part of the truth condition of the given proposition. This is supported by the fact that the denial sore-wa uso-da 'No, that's false' can target the comparative meaning in (10). I assume that in Japanese comparative, the standard marker yori encodes a comparative meaning (Kennedy 2007; Hayashishita 2009; Sawada 2013):

$$
[[\text { yori }]]=\lambda x \lambda g \lambda y \cdot \max \left\{d^{\prime} \mid g\left(d^{\prime}\right)(y)\right\}>\max \left\{d^{\prime} \mid g\left(d^{\prime}\right)(x)\right\}
$$

As for the meaning of a gradable predicate, I assume that gradable predicates represent relations between individuals and degrees (e.g., Klein 1991; Kennedy and McNally 2005).

$$
[[\text { ookii }]]=\lambda d \lambda x \cdot \operatorname{big}(x)=d
$$

Note that as I have briefly explained in the introduction, the particle mo is meaningless in soreyori- $(\mathrm{mo})$ and it does not affect the meaning of a sentence. The following figure shows the logical structure of (10):

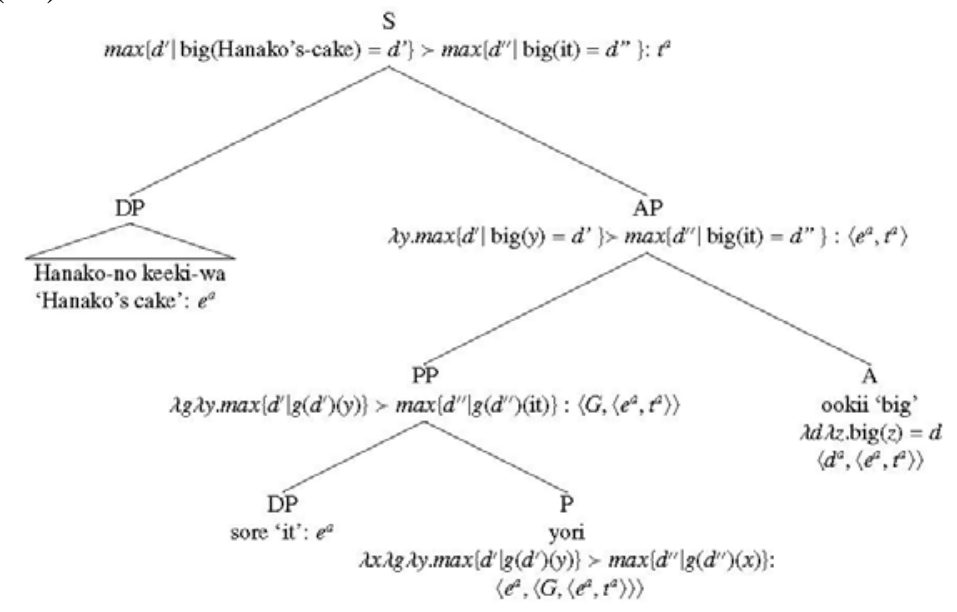

2.2. THE MEANING OF THE PRAGMATIC SORE-YORI-(MO). Now, let us start investigating the meaning and use of the pragmatic sore-yori- $(\mathrm{mo})$. As we observed in Introduction, the pragmatic 
sore-yori-(mo) has goal-shifting and non-goal shifting uses. In the lexical level, I argue that both goal-internal and goal-shifting uses of sore-yori have the same CI; that is, "the at-issue utterance is more important than the previous utterance":

(14) (Example of the pragmatic sore-yori-(mo) (non-topic shifting))

Question: What kind of tennis player is Taro?

A: Taro-wa foaa-ga umai-desu.

Taro-TOP forehand-NOM good-PRED.HON

'Taro is good at his forehand stroke.'

B: Iya, sore-yori-(mo) (mazu) Taro-wa saabu-ga sugo-sugi-desu.

No that-than-MO first Taro-TOP service-NOM great-too-PRED.HON

At-issue: No, Taro is extremely great at his serve.

CI: My utterance is more important than your utterance.

(15) (Example of the pragmatic sore-yori-(mo) (topic shifting))

A:Sensei osoi-ne?

Teacher late-confirm.Q

'The teacher is late, isn't she?'

B: Sore-yori-(mo) kinoo-no tesuto saiaku-da-tta.

It-than-MO yesterday-GEN test terrible-PRED-PAST

At-issue: Yesterday's exam was terrible.

CI: My utterance is more important than your utterance.

In the Gricean theory of meaning, CIs are considered as part of the meaning of words, yet these meanings are not part of "what is said” (e.g., Grice 1975; Potts 2005, Potts 2007; McCready 2010; Gutzmann 2015; Horn 2013; Sawada 2010, 2018). Furthermore, CIs have the semantic property of speaker-orientedness (by default) (Potts 2005, Potts 2007).

The pragmatic sore-yori-mo satisfies these criteria. First, the pragmatic use of sore-yorimo is invariably speaker-oriented. Second, its meaning is logically and dimensionally independent of "what is said." This is supported by the fact that the meaning triggered by the pragmatic sore-yori cannot be challenged by the utterance "Not, that's not true.”

(16) Iya sore-wa uso-da.

No that-TOP false-PRED

'No, that's false.'

Unlike semantic sore-yori-(mo), the denial cannot target the comparative meaning triggered by the pragmatic sore-yori in (14B) and (15B). It can only target the at-issue part of the B's utterance. Furthermore, the fact that the meaning triggered by sore-yori cannot be within the semantic scope of logical operators (such as past tense in (15B)) also supports that the pragmatic/discourse use of sore-yori is independent of "what is said."

Now, let us consider how the meaning of pragmatic sore-yori-(mo) is interpreted. First, I assume that there is another yori 'than' for a speech act modifier:

$$
\begin{aligned}
& {\left[\left[\text { yori }_{\text {PRAG }}\right]\right]:\left\langle a^{a},\left\langle a^{a}, t^{s}\right\rangle\right\rangle} \\
& =\lambda U \lambda U^{\prime} . \max \left\{d^{\prime} \mid \operatorname{important}\left(U^{\prime}\right)=d^{\prime}\right\}>\max \left\{d^{\prime} \mid \operatorname{important}(U)=d^{\prime}\right\}
\end{aligned}
$$

The non-superscript $a$ is the type for speech act; $U$ and $U$ ' are the variables for type $a$; superscript $a$ stands for the at-issue type; and superscript $s$ stands for the shunting type. The pragmatic use of yori compares two utterances (speech acts) as its arguments and conventionally 
implicates that the maximum degree to which the second utterance is important is greater than the maximum degree to which the first utterance is important. ${ }^{4}$ Notice that in the pragmatic soreyori-mo, the measure function "important" is built in the lexicon. No explicit gradable predicate is combined with yori. The pragmatic yori then combines with sore, which refers to a previous utterance:

(18) $[[$ sore $]]: a^{a}=U_{\mathrm{PRE}}$ ( $U_{\mathrm{PRE}}$ stands for the previous utterance)

Sore and yori are then combined via the shunting operation (McCready 2010; Gutzmann 2012):

(19) The shunting application (McCready 2010)

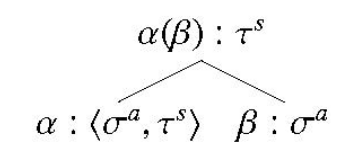

(20) $\left[[\right.$ yori] $]([[$ sore $]]):\left\langle a^{a}, t^{s}\right\rangle$

$=\lambda U^{\prime} . \max \left\{d^{\prime} \mid \operatorname{important}\left(U^{\prime}\right)=d^{\prime}\right\}>\max \left\{d^{\prime} \mid \operatorname{important}\left(U_{\mathrm{PRE}}\right)=d^{\prime}\right.$,

The superscript $a$ stands for the at-issue type, and the superscript $s$ stands for the shunting type. The shunting type $s$ is utilized for the interpretation of a special kind of CI content. The rule says that an $\alpha$ of type $\left\langle\sigma^{a}, \tau^{s}\right\rangle$ takes $\beta$ of type $\sigma^{a}$ and returns $\tau^{s}$. Note that this rule is specific to certain CI meanings, namely, resource-sensitive CI. The rule is different from Potts's (2005) CI function application, which is resource-insensitive. Sore-yori then combines with a main utterance. As for the semantic representation of a speech act, following Stenius (1967) and Krifka (2001), I will assume the following type system. (22) shows the logical structure of (15B):

(21) a. Basic types: $e$ entities, $t$ truth values, $p(=s t)$ propositions, $a$ speech acts.

b. A speech act operator is a function from the type of sentence radical it selects to type $a$.

c. The variables for type $a=\left\{U, U^{\prime}, U^{\prime}, \ldots\right\}$

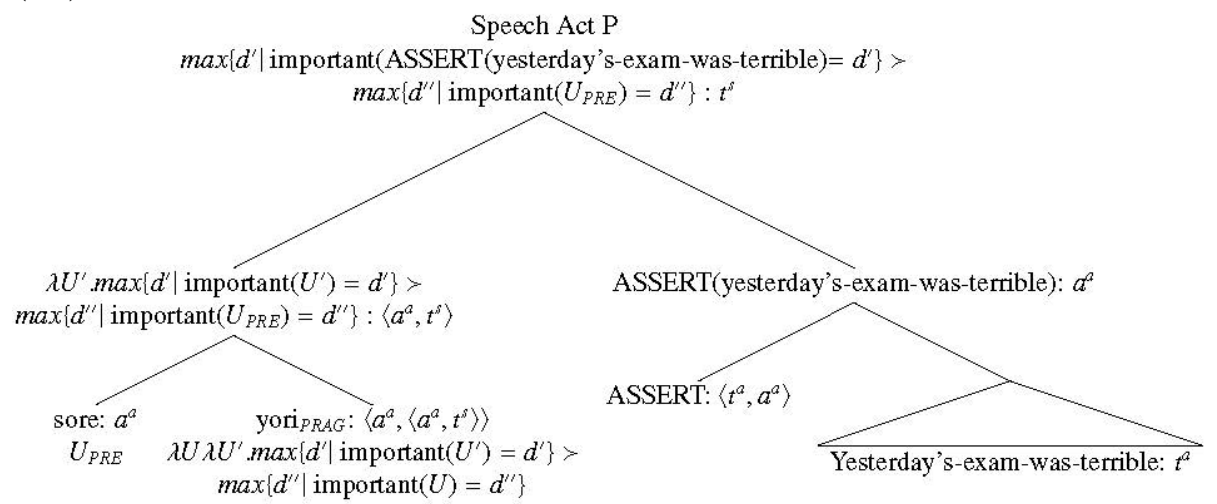

One problem with this analysis is that the at-issue speech act (i.e., question) is not represented at the root level even though it is performed. I propose that the following interpretive rule applies to the embedded speech act:

\footnotetext{
${ }^{4}$ Note that pragmatic sore-yori is different from the metalinguistic comparative to iu-yori-mo in (i)(Sawada 2014):

(i) Taro-wa sensei-to iu-yori-mo gakusha-da

Taro-TOP teacher-that say-than-MO scholar-PRED

'Taro is more a scholar than a teacher.'
} 
(23) Projection of a speech act: Interpret " $F(U): t^{s "}$ as

$$
\begin{gathered}
U: a^{a} \\
\bullet \dot{F}(U): t^{s}
\end{gathered}
$$

In the case of sore-yori, F corresponds to sore-yori-mo. By applying this rule to the root in (22), in the end, we get the following two-dimensional meanings:

QUEST(you-finish-your-homework): $a^{a}$

$\max \left\{\mathrm{d}^{\prime} \mid\right.$ important(QUEST(you-finish-your-homework) $=\mathrm{d}^{\prime}>\max \left\{\mathrm{d}^{\prime} \mid \operatorname{important}\left(\mathrm{U}_{\mathrm{PRE}}\right)=\mathrm{d}^{\prime \prime}\right\}: t^{s}$

2.3. DERIVING THE PRAGMATIC FUNCTIONS OF THE PRAGMATIC SORE-YORI-(MO). The question is how to distinguish between goal-shifting and goal-internal comparisons. I argue that the distinction between goal-shifting comparison and goal-internal comparison is determined by Grice's maxim of relevance; namely, it is determined by the extent to which $U$ in sore-yori $(U)$ is relevant to the "current” Question Under Discussion (QUD)(e.g., Roberts 1996). If the given utterance (the utterance associated with sore-yori) is less relevant to the current QUD, the comparison by sore-yori is interpreted as more goal shifting. For example, sore-yori-(mo) in (14) is interpreted as goal internal because the at-issue utterance is relevant to the current QUD (What kind of tennis player is Taro?). On the other hand, sore-yori-(mo) in (15) is interpreted as goal shifting because the given utterance is not directly related to the current QUD (The teacher is late, isn't she?). I would like to assume that sore-yori-mo in (15) is implicitly answering to a new QUD "What do you want to say?"

Note that goal-internal and goal-shifting comparison can be a continuum. The following example illustrates a goal-shifting comparison, but it is also pragmatically connected to the previous utterance (which itself is a QUD):

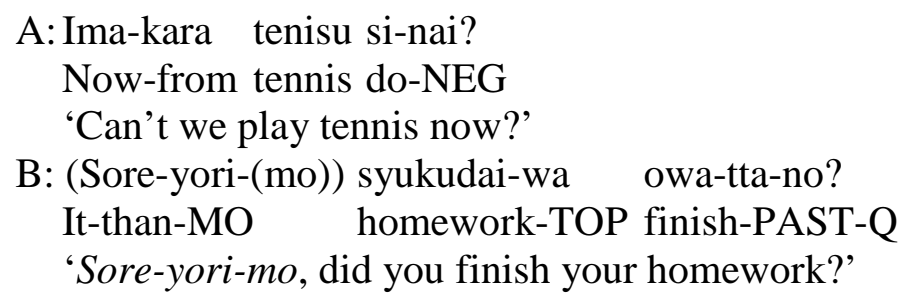

Here, $\mathrm{B}$ is asking a new question (i.e., introducing a new QUD), so it is natural to consider that the utterance is a goal-shifting comparison. Although B is introducing a new QUD, B's utterance is relevant to A's utterance (the QUD). Whether A can play tennis or not depends on whether A has finished his/her homework. The idea that B's question is relevant to A's utterance is supported by the fact that the utterance sounds natural even if we delete sore-yori-mo. This fact supports the idea that the distinction between goal-internal and goal-shifting comparisons is purely a matter of pragmatics.

3. The Japanese nani-yori-mo. Let us now turn our attention to nani-yori-mo.

3.1 THE MEANING OF THE SEMANTIC NANI-YORI-MO. Before considering the interpretive mechanism of the pragmatic nani-yori-(mo), let us first examine the meaning of the semantic 
nani-yori-mo based on the following example: ${ }^{5}$

(26) Tennis-wa nani-yori-mo tanoshii.

Tennis-TOP what-than-MO fun

'Tennis is more fun than anything.'

The semantic nani-yori-mo uses the same lexical item yori as the semantic sore-yori-mo:

$$
[[\text { yori }]]=\left\{\lambda x \lambda g \lambda y \cdot \max \left\{d^{\prime} \mid g\left(d^{\prime}\right)(y)\right\}>\max \left\{d^{\prime \prime} \mid g\left(d^{\prime \prime}\right)(x)\right\}\right\}
$$

What is different from the semantic sore-yori-mo is that the semantic nani-yori-mo combines with the indeterminate pronoun nani, which denotes a set of alternative individuals:

$$
[[\text { nani }]]=\{x \mid x \in \text { thing } \wedge C(x)\}
$$

A contextual operator $C$ ensures that nani 'what' only introduces contextually relevant alternatives. In analyzing the meaning of nani-yori, I use Hamblin’s 1973 semantics for Japanese indeterminate pronouns (Kratzer and Shimoyama 2002; Shimoyama 2006) where nani combines with yori via pointwise application:

(29) Pointwise Functional Application (Kratzer and Shimoyama 2002):

If $\alpha$ is a branching node with daughters $\beta$ and $\gamma$, and $[[\beta]] \subseteq D_{\sigma}$ and $[[\gamma]] \subseteq D_{\langle\sigma, \tau\rangle}$, then $[[\alpha]]=$ $\left\{a \in D_{\tau}: \exists b \exists c[b \in[[\beta]] \wedge c \in[[\gamma]] \wedge a=c(b)]\right\}$

If we apply this functional application to nani-yori in the individual reading, we can derive the following meaning (Note that yori in (27) is a singleton set):

(30) The interpretation of nani-yori via pointwise function application

nani-yori

yori(soccur),yori(baseball), ..., yori(basketball)

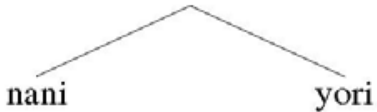

\{soccer, baseball, basketball, ... $\quad$ yori\}

Note that the alternatives expand until they meet the universal operator mo, which selects them:

$$
[[\mathrm{mo}]]=\{\lambda P \lambda g \lambda y . \forall x[x \in \text { thing } \rightarrow P(g)(y)]\}
$$

Thus, if mo is combined with nani-yori, we get the following meaning:

$$
\begin{aligned}
& {[[\mathrm{mo}]]([[\text { nani-yori }]])=} \\
& \{\lambda g \lambda z . \forall x[x \in \text { thing } \rightarrow \max (g)(z)>\max (g)(x)] \mid x \in \text { thing } \wedge C(x)\}
\end{aligned}
$$

Nani-yori-mo is then combined with the gradable predicate tanishii 'fun', which denotes a singleton set:

\footnotetext{
${ }^{5}$ Unlike sore-yori-mo, for many native speakers, mo is necessary in the semantic nani-yori-mo. Furthermore, note that various kinds of indeterminate pronouns can be used for the semantic comparison:

(i) Hanako-wa dare-yori-??(mo) yasashii.

Hanako-TOP who-than-MO kind

'Hanako is more kind than anyone.'

(ii) Tokyo-wa nihon-no doko-yori-??(mo) benri-da.

Tokyo-TOP Japan-GEN where-than-MO convenient-PRED

'Tokyo is more convenient than anywhere in Japan.'
} 


$$
[[\text { tanoshii }]]=\{\lambda d \lambda x . \text { fun }(x)=d\}
$$

The following figure shows the logical structure of (26):

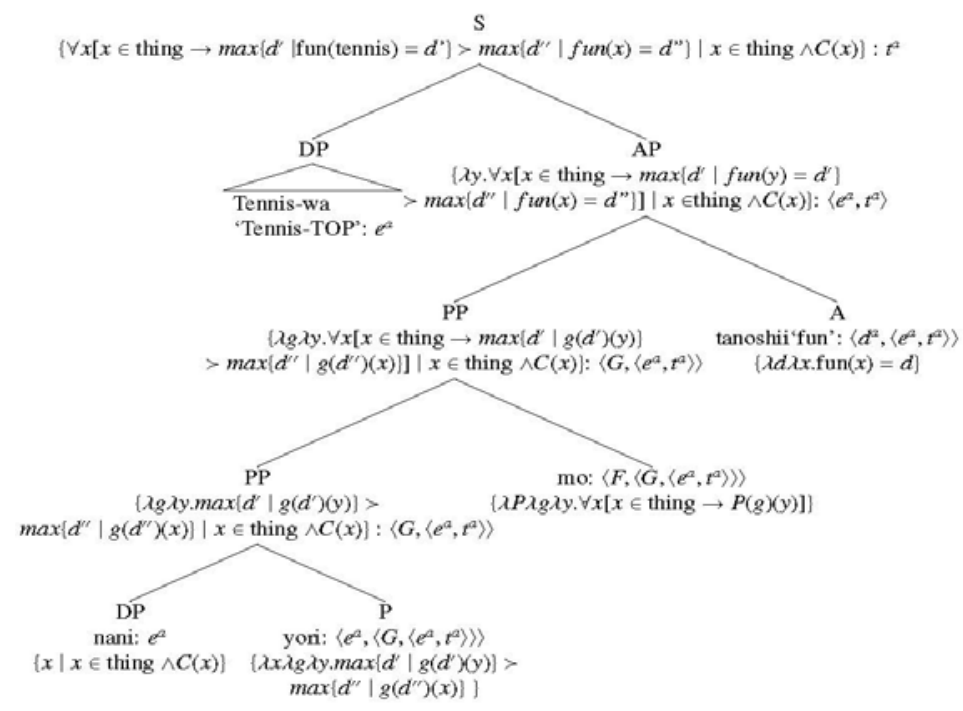

3.2. THE MEANING OF THE PRAGMATIC NANI-YORI-(MO). Let us now turn our attention to the pragmatic nani-yori- $(\mathrm{mo})$. Similar to the case of the pragmatic sore-yori-(mo), the pragmatic nani-yori is a CI-triggering expression. The pragmatic nani-yori-(mo) conventionally implicates that the at-issue utterance is more important than any alternative utterance:

Nani-yori-mo Shizuoka-wa atatakai.

What-than-MO Shizuoka-TOP warm

'More than anything, Shizuoka is warm.'

The idea that it is independent from "what is said" is supported by the fact that the denial cannot target the meaning of noteworthy comparison. For example, if we say "no, that's not true" after the noteworthy comparative utterance, the denial can only target the at-issue part of the utterance (i.e., Tokyo is safe):

(36) Iya, sore-wa uso-desu.

No that-TOP false-PRED.HON

'No, that's false.' (Tokyo is not safe.)

Note that in the case of the semantic nani-yori-mo, a denial can target the comparative meaning. Let us now consider how the meaning of the pragmatic nani-yori-( $\mathrm{mo})$ is computed. I argue that the meaning of the pragmatic nani-yori- $(\mathrm{mo})$ can be derived based on the same lexical item yori in the pragmatic nani-yori-mo:

$$
[[\text { yoripraG }]]=\left\{\lambda U \lambda U^{\prime} \max \left\{d^{\prime} \mid \operatorname{important}\left(U^{\prime}\right)=d^{\prime}\right\}>\max \left\{d^{\prime} \mid \operatorname{important}(U)=d^{\prime}\right\}\right\}
$$

The superlative meaning of the pragmatic nani-yori-mo is derived by the meaning of nani and the universal particle mo. As for nani, I assume that it denotes a set of speech act:

$$
[[\text { nani }]]=\{U \mid U \in \text { speech act } \wedge C(U)\}
$$

Then, the pragmatic nani-yori is combined with mo, which selects all the alternatives created by nani in (38): 
(39)

[[mo]]: $\left\langle\left\langle a^{a}, t^{s}\right\rangle,\left\langle a^{a}, t^{s}\right\rangle\right\rangle=\left\{\lambda O \lambda U^{\prime} . \forall U\left[U \in\right.\right.$ speech act $\left.\left.\rightarrow O\left(U^{\prime}\right)\right]\right\}$

The CI meaning in (39) is then combined with the main part of the utterance, the speech act. The following figure shows the logical structure of (35):

(40) The logical structure of the sentence with the pragmatic nani-yori-(mo)

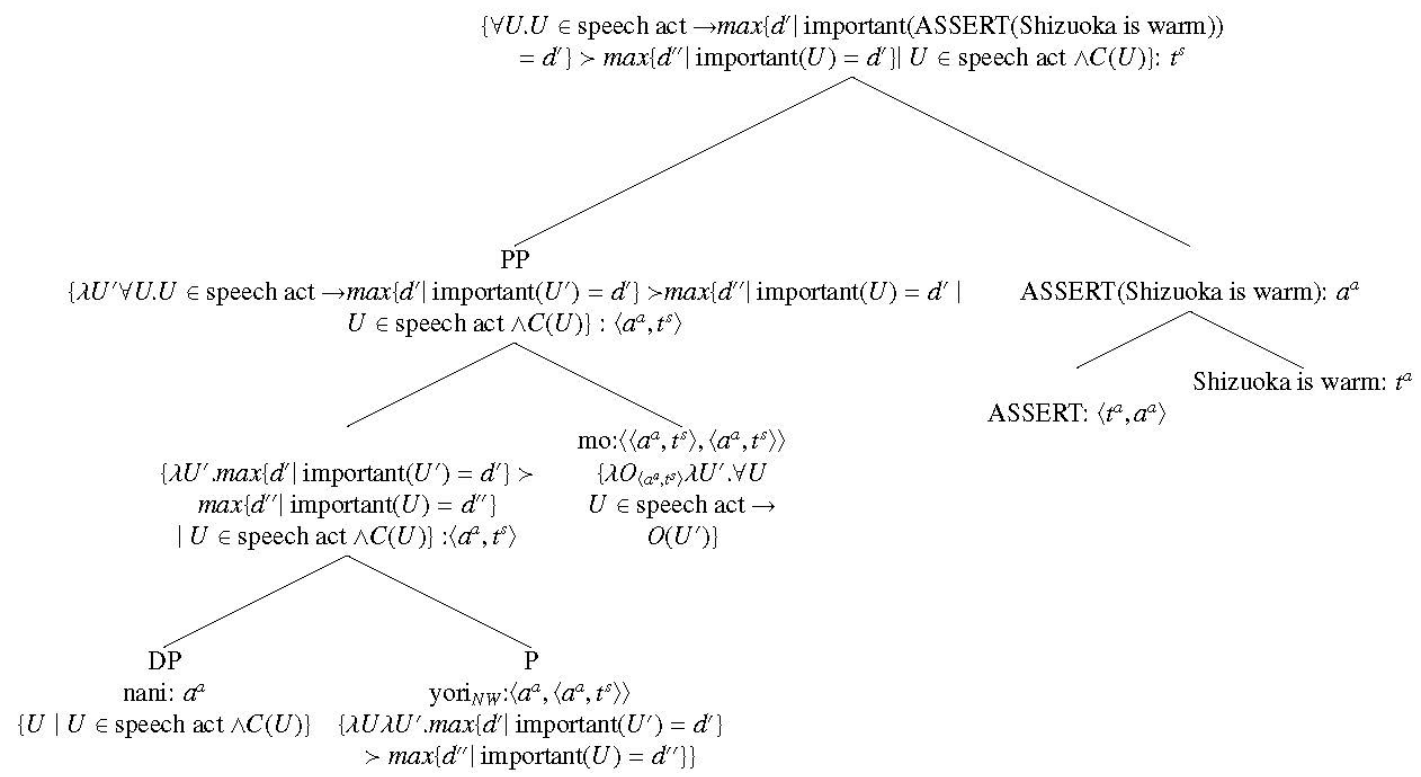

As in the case of the pragmatic sore-yori-mo, the argument of nani-yori (i.e., the at-issue speech act) is projected to the root level via the "projection of a speech act":

\{ASSERT(Shizuoka is warm)\}: $a^{a}$

$\left\{\forall U . U \in\right.$ speech act $\rightarrow \max \left\{d^{\prime} \mid \operatorname{important}\left(\right.\right.$ ASSERT(Shizuoka is warm)) $\left.=d^{\prime}\right\}>\max \left\{d^{\prime \prime} \mid \operatorname{important}(U)=\right.$ $d "\} \mid U \in$ speech act $\wedge C(U)\}: t^{s}$

One puzzling point is that unlike the semantic nani-yori- $(\mathrm{mo})$, mo is optional in the case of the pragmatic nani-yori-(mo). I would like to consider that $m o$ is optional in the pragmatic naniyori-mo, because the indeterminate pronoun nani 'what' is the only possible indeterminate pronoun that can be used at the CI level (nani is a speech act, but other indeterminate pronouns are not). In the case of the pragmatic nani-yori-mo, mo takes a CI-triggering expression to trigger a CI meaning, but this semantic operation is computationally redundant if we consider that mo always take nani-yori as its argument. There is a possibility that the pragmatic nani-yori-mo has been conventionalized, and as a result, mo can be dropped in the pragmatic use.

3.3. DERIVING THE PRAGMATIC FUNCTIONS OF THE PRAGMATIC NANI-YORI-MO. Let us nOW consider the discourse-dependent pragmatic functions of nani-yori-mo. As we have observed earlier, nani-yori can be placed at the beginning of a discourse sequence, which creates a "priority listing" effect (i.e., the top-down strategy), or it can be placed at the end of a discourse sequence, which creates an "additive reinforcing" effect (i.e., the bottom-up strategy):

(42) Top-down strategy (priority listing)

A:Tokyo-no ii tokoro-tte nan-desu-ka?

Tokyo-GEN good point-TE what-PRED.POL-Q

'What is a good point of Tokyo?' 
B: Soo-desu-nee. Nani-yori-mo Tokyo-wa anzen-desu.

Let's see what-than-MO Tokyo-TOP safe-PRED.POL

Soreni benri-mo ii-desu.

Also convenience-also good-PRED.HON

'Let's see. More than anything, Tokyo is safe. Furthermore, Tokyo is convenient.'

(43) Bottom-up strategy (additive reinforcing)

A: Tokyo-no ii tokoro-tte nan-desu-ka?

Tokyo-GEN good point-TE what-PRED.POL-Q

'What are the good points of Tokyo?'

B: Soo-desu-ne. Tokyo-wa benri-ga ii-si nigiyaka-desu.

Let's see Tokyo-TOP convenience-NOM good-and lively-PRED.HON

Sosite nani-yori-mo, Tokyo-wa anzen-desu.

And what-than-MO Tokyo-TOP safe-PRED.POL

'Let's see. Tokyo is convenient, and it is lively. And more than anything, Tokyo is safe.'

I propose that the functions of "priority listing" and "additive reinforcing" naturally arise by obeying the Grice's maxim of manner: Be orderly. Because of the maxim of manner, the only possibility to place the most important information in order is to signal it at either the beginning or the end of a discourse sequence. This means that the maximum endpoint of the importance scale is mapped onto the edge of a temporal scale of a discourse, that is, the beginning or the end.

4. Relationship between sore-yori-(mo) and nani-yori-(mo). In sections 2 and 3 , we discussed the meaning and use of the pragmatic sore-yori- $(\mathrm{mo})$ and nani-yori- $(\mathrm{mo})$ and considered how their pragmatic functions are pragmatically derived. The theoretical implication we get from our analysis is that the discourse-dependent pragmatic functions of sore-yori and nani-yori are restricted by their scale structures (which is represented at the CI level.)

a. Non-maximum endpoint scale

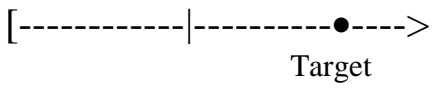

b. Maximum endpoint scale

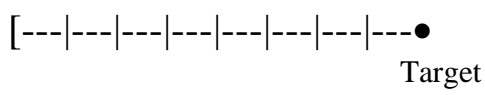

("|" stands for a standard of comparison.)

That is, scalar structures are the input for deriving pragmatic functions. This predicts that soreyori- $(\mathrm{mo})$ and nani-yori- $(\mathrm{mo})$ cannot trigger the same pragmatic effects because the inputs are different; thus, this prediction is supported. As the following example shows, the pragmatic naniyori, but not the pragmatic sore-yori, is awkward in the context of goal shifting:

(Context of goal shifting))

A: Sensei osoi-ne?

Teacher late-confirm.Q

'The teacher is late, isn't she?'

B: $\{$ Sore-yori(-mo)/\# nani-yori(-mo)\} kinoo-no tesuto saiaku-da-tta.

It-than-MO / what-than-MO yesterday-GEN test terrible-PRED-PAST

'\{Sore-yori-mo/\#nani-yoi-mo\}, yesterday's exam was terrible.' 
The pragmatic nani-yori(-mo) is inappropriate for goal shifting because nani 'what' is indefinite, and it cannot refer to a previous utterance. It just conventionally implicates that the at-issue utterance is the most important among other possible utterances.

By contrast, sore-yori- $(\mathrm{mo})$, but not nani-yori-( $\mathrm{mo})$, cannot trigger a function of priority listing nor can it have a function of additive reinforcing because these functions require a scale that has multiple standards:

(46) (Context of priority listing)

A: What are the good points of Shizuoka?

B: $\{$ Nani-yori(-mo) /\# Sore-yori(-mo)\} Shizuoka-wa ondan-desu. Soreni What-than-MO / It-than-MO Shizuoka-TOP warm-PRED.HON also tabemono-mo oishii-desu. Kootuu-no ben-mo yoifood-also good-PRED.HON. Transportation-GEN convenience-also gooddesu. PRED.HON

'More than anything, Shizuoka is warm. Furthermore, food is good. Also, it is easy to access.'

(47) (Context of additive reinforcing)

A: What are the good points of Shizuoka?

B: Soodesune. Shizuoka-wa koutuu-no ben-ga ii-desu.

Let's see Shizuoka-TOP transportation-GEN convenience-NOM good-PRED.HON Tabemono-mo oishii-desu. Soshite \{nani-yori-(mo)/\# sore-yori-(mo)\}

Food-also good-PRED.HON And what-than-MO/ it-than-MO

Shizuoka-wa ondan-desu.

Shizuoka-TOP warm-PRED.HON

'Let's see. Shizuoka is easy to access. The food is also good. And more than anything, Shizuoka is warm.'

Note that in the following conversation, both sore-yori and nani-yori- $(\mathrm{mo})$ can naturally be used:

(48) (Context of denial in goal-internal comparison) [Question: What kind of person is Taro?]

A:Taro-wa atama-ga ii-desu.

Taro-TOP head-NOM good-PRED.HON

'Taro is smart.'

B: Iya, \{sore-yori(-mo)/nani-yori-(mo)\} mazu Taro-wa yasashii hito-desu.

No that-than-MO what-than-MO first Taro-TOP kind person-PRED.HON

'No, sore-yori-mo/nani-yori-mo, first, Taro is a kind person.'

In this context, speaker B is denying A's utterance based on the goal-internal comparison. In this case, the use of nani-yori-(mo) is appropriate. Note, however, that the negative response marker iya 'no' is obligatory in the case of nani-yori- $(\mathrm{mo})$. Nani-yori- $(\mathrm{mo})$ is not referring to the previous utterance, but iya signals a negative response to the previous utterance.

Interestingly, both nani-yori- $(\mathrm{mo})$ and sore-yori- $(\mathrm{mo})$ can co-occur in the same sentence; however, there is an asymmetry in the ordering in that sore-yori- $(\mathrm{mo})$ has to come first:

(49) (Context of denial in goal-internal comparison) [Question: What kind of person is Taro?]

A: Taro-wa atama-ga ii-desu.

Taro-TOP head-NOM good-PRED.HON

'Taro is smart.' 


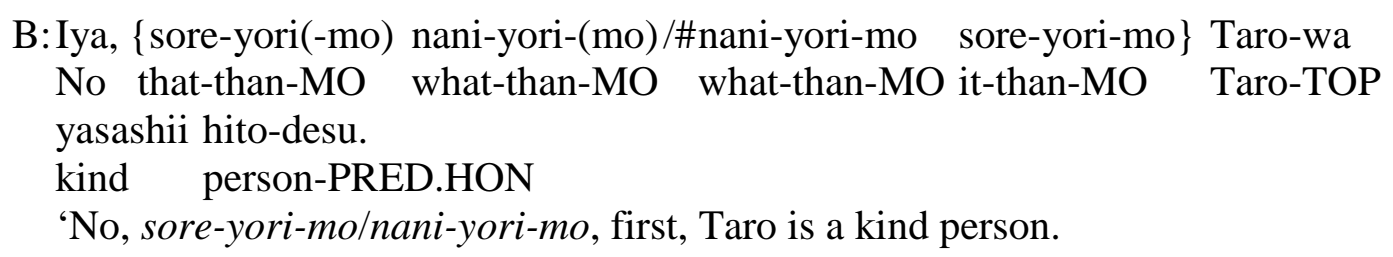

This seems to be explained based on information updating. In order to refer to the previous utterance, we need to first use sore-yori. If we first introduce nani-yori-mo, then it will compare every alternative, thus it is meaningless to refer to one specific utterance after a universal comparison.

5. Comparison to English pragmatic comparative expressions. We have considered the meanings and uses of the two kinds of comparative expressions in Japanese. Finally, let us briefly consider cross-linguistic variation of pragmatic comparative expressions by comparing Japanese and English data. Similar to Japanese, English also has pragmatic comparative expressions such as more than that and more than anything. The former can serve as an utterance modifier as in (50):

(50) I felt happy. More than that, I felt relieved.

However, unlike sore-yori, it cannot be used in the context of rejecting a previous utterance:

(51) A: What kind of person is Hanako?

B: Hanako is smart.

C: No, \{??more than that/rather than that $\}$, Hanako is a kind person.

Furthermore, the English more than that does not have the goal-shifting function:

(52) (Context of goal-shifting comparison)

A: Can't we play tennis?

B: $\{\#$ More than that/rather than that/instead of that $\}$ did you finish your homework?

In this context, the expressions such as instead of that or rather than that are more natural.

However, as for English more than anything, it seems that its meaning and function are the same as those of the Japanese pragmatic nani-yori-mo. As the following examples show, more than anything has both "priority listing" and "additive reinforcing" functions:

(53) Example of more than anything (top-down strategy) More than anything she is a Personal Achiever, where she scores unusually high. She is also very high as a Real Manager and as an Expert Idea Generator. (https://books.google.co.jp/books?isbn=1881052826)

(54) Example of more than anything (bottom-up strategy) I want to show the U.S. Ski Team how I can ski, I want to show the country how I can ski, and more than anything, I want to show the diabetes community what's possible. I really did not want to have a blood-sugar episode on the biggest stage. I wanted this to be "You can do anything with this disease' — and I still totally believe that—but there are setbacks along the way. I got one more chance. (http://sportsillustrated.cnn.com/2010/olympics/2010/writers/david_epstein/02/23/freeman .diabetes/index.html)

How can we explain the similarities and differences between English and Japanese pragmatic comparatives? I would like to claim that the English standard markers more than and Japanese 
yori in their pragmatic use have different meanings in the former, but not the latter, which has an additional additive component in that the standard of comparison satisfies a contextual standard of importance (I tentatively assume that the additive component is a presupposition): ${ }^{6}$
a. English: [[more than $\left.\left.{ }_{\mathrm{PRAG}}\right]\right]=$ $\lambda U \lambda U^{\prime}: \exists d[d \geq \operatorname{STAND} \wedge \operatorname{important}(U)=d] . \max \left\{d^{\prime} \mid \operatorname{important}\left(U^{\prime}\right)=d^{\prime}\right\}>\max \left\{d^{\prime \prime} \mid\right.$ $\left.\operatorname{important}(U)=d^{\prime}\right\}$ (where $U$ and $U^{\prime}$ are relevant to a goal of conversation)
b. Japanese: [[yoripRAG $]$ ] =
$\lambda U \lambda U^{\prime} . \max \left\{d^{\prime} \mid \operatorname{important}\left(U^{\prime}\right)=d^{\prime}\right\}>\max \left\{d^{\prime} \mid \operatorname{important}(U)=d^{\prime}\right\}$

However, essentially, when yori and more than are used in endpoint-oriented comparatives, their difference is neutralized. Both more than anything and nani-yori-mo denote that the given utterance is the most important among other alternatives; thus, they have the same superlative CI meaning and the same pragmatic functions (although there is a difference between them in the scalar value of alternatives.)

\section{Conclusion}

This paper investigated the discourse-pragmatic uses of Japanese comparative expressions soreyori-( $\mathrm{mo})$ and nani-yori-( $\mathrm{mo})$ and considered their discourse-dependent pragmatic functions. I argued that the pragmatic sore-yori- $(\mathrm{mo})$ is non-endpoint-oriented in that it conventionally implicates that the given utterance is more important than the previous utterance, whereas the pragmatic nani-yori- $(\mathrm{mo})$ is endpoint-oriented in that it compares the given speech act with every contextually relevant alternative utterance. I then argued that the discourse pragmatic effects of each pragmatic comparative expression (such as topic shifting in sore-yori- $(\mathrm{mo})$ and priority listing or additive reinforcing in nani-yori) automatically arise from the interaction between their scale structures (which are represented at the level of conventional implicature (CI)) and general pragmatic principles). This paper clarified that scale structures are utilized for various pragmatic purposes, and that scale structures play a crucial role in managing the direction of discourse. Furthermore, this paper also suggests that there is a rich interaction between CIs and general conversational maxims in natural language; therefore, it is important to examine both kinds of implicatures at the same time to understand fully the rule of CI expressions. In the future, I would like to investigate the mechanism of mapping from scale structure and discourse structure more theoretically and consider whether there can be pragmatic functions other than the discussed pragmatic functions in the pragmatic sore-yori-(mo) and nani-yori-(mo).

\section{References}

Greenberg, Yael. 2010. Additivity in the domain of eventualities. In Martin Prinzhorn, Viola Schmitt and Sarah Zobel (eds.), Proceedings of Sinn und Bedeutung 14. 151-167.

Grice, Paul H. 1975. Logic and conversation. In Peter Cole \& Jerry L. Morgan (eds.), Syntax and semantics III: Speech acts, 43-58. New York: Academic Press.

Gutzmann, Daniel. 2015. Use-conditional meaning: Studies in multidimensional semantics. Ox-

\footnotetext{
${ }^{6}$ It seems that it is not a coincidence that the pragmatic more than that has an additive component. As Thomas (2010) and Greenberg (2010) have observed, the English more has both comparative and additive (incremental) use. For example, in the additive (incremental) reading (i), the second sentence asserts that there are two beers in the fridge and presupposes that there are/were some other beers:

(i) There were five beers on the kitchen table. There are two more in the fridge. (Thomas 2010)

It seems that the pragmatic more than that is similar to the additive/incremental more in that it is adding additional information to the previous utterance.
} 
ford: Oxford University Press.

Hamblin, Charles L. 1973. Questions in montague english. Foundations of Language 10. 41-53.

Hayashishita, J-R. 2009. Yori-comparatives: A reply to Beck et al. (2004). Journal of East Asian Linguistics 18. 65-100.

Horn, Laurence R. 2013. I love me some datives: Expressive meaning, free datives, and fimplicature. In Daniel Gutzmann \& Hans-Martin Gärtner (eds.), Beyond expressives: Explorations in use-conditional meaning, 151-199. Leiden/Boston: Brill.

Kawabata, Motoko. 2002. Ridatu kara tenkan e: wadai tankan kinoo o kakutoku sita sore-yori ni tuite (sore-yori as a topic-changing conjunction: how sore-yori captures the modal meaning). Kokugogaku 53. 48-62.

Kennedy, Christopher. 2007. Standards of comparison. Handout of Colloque de Syntaxe et Sémantique à Paris.

Kennedy, Christopher \& Louise McNally. 2005. Scale structure, degree modification, and the semantics of gradable predicates. Language 81. 345-381. DOI: 10.1353/lan.2005.0071.

Klein, Ewan. 1991. Comparatives. In Arnim von Stechow \& Dieter Wunderlich (eds.), Semantik: Ein internationales handbuch der zeitgenossischen forschung, 673-691. Berlin: Walter de Gruyter.

Kratzer, Angelika \& Junko Shimoyama. 2002. Indeterminate pronouns: the view from japanese. In Yukoi Otsu (ed.), Proceedings of the Third Tokyo Conference on Psycholinguistics, 1-25.

Krifka, Manfred. 2001. Quantifying into question acts. Natural Language Semantics 9. 1-40. https://doi.org/10.1023/A:1017903702063.

McCready, Eric. 2010. Varieties of conventional implicature. Semantics \& Pragmatics 3. 1-57. http://dx.doi.org/10.3765/sp.3.8.

Potts, Christopher. 2005. The logic of conventional implicatures. Oxford: Oxford University Press.

Potts, Christopher. 2007. The expressive dimension. Theoretical Linguistics 33. 165-197. https://doi.org/10.1515/TL.2007.011.

Roberts, Craige. 1996. Information structure: towards an integrated formal theory of pragmatics. In Jae Hak Yoon \& Andreas Katholeds (eds.), OSU WPL volume 49: Papers in semantics, Columbus, OH: The Ohio State University Department of Linguistics.

Sawada, Osamu. 2018. Pragmatic aspects of scalar modifiers: The semantics-pragmatics inter face. Oxford: Oxford University Press.

Sawada, Osamu. 2014. The degree of the speaker's negative attitude in a goal-shifting compare son. Proceedings of the 15th Texas Linguistics Society Conference, 150-169.

Sawada, Osamu. 2013. The comparative morpheme in Modern Japanese: looking at the core from 'outside.' Journal of East Asian Linguistics 22(3). 217-260. https://doi.org/10.1007/s10831-013-9104-4.

Sawada, Osamu. 2010. Pragmatic aspects of scalar modifiers. Chicago, IL: University of Chicago dissertation.

Shimoyama, Junko. 2006. Indeterminate phrase quantification in Japanese. Natural Language Semantics 14. 139-173. https://doi.org/10.1007/s11050-006-0001-5.

Stenius, E. 1967. Mood and language-game. Synthese 17. 254-274.

Thomas, Guillaume. 2010. Incremental more. Proceedings of Semantics and Linguistic Theory 20. 233-250. http://dx.doi.org/10.3765/salt.v20i0.2558.

Vanderveken, D. 2013. Towards a formal pragmatics of discourse. International Review of Pragmatics 5. 34-69. 